\title{
Theoretical and Experimental Studies on Anticancer Drug Mitoxantrone
}

\author{
Jamelah S. Al-Otaibi ${ }^{\mathrm{a}}$, Yahya Wasli ${ }^{\mathrm{b}}$ and Tarek M. EL Gogary ${ }^{\mathrm{b}, \mathrm{c}, \mathrm{d}^{*}}$ \\ ${ }^{\text {a }}$ Department of Chemistry, College of Science, Princess Nourah bint Abdulrahman \\ University, Riyadh 11951, Saudi Arabia. \\ ${ }^{\mathrm{b}}$ Department of Chemistry, Faculty of Science, Jazan University, Jazan, Saudi Arabia. \\ ${ }^{c}$ School of Allied Health Science, Faculty of Health and Life Sciences, De Montfort \\ University, Leicester, UK. \\ ${ }^{\mathrm{d}}$ Permanent address: Department of Chemistry, Faculty of Science, Damietta University, \\ New Damietta city, Egypt. \\ ${ }^{*}$ Corresponding author
}

Abstract- Mitoxantrone (MX) is an important antineoplastic drug used for treatment of different types of cancer with lower side effects. The purpose of this study is to shade more light on the mechanism of interaction between $\mathbf{M X}$ and biological molecules. This study would result in drug design and development. Molecular structure was computed at the B3LYP/6-31+G(d) level. All possible intramolecular hydrogen bonding interactions were considered and calculated at the same level. Five conformers of MX were located and computed to lie in the energy range $0.000-48.495 \mathrm{kcal} / \mathrm{mol}$. Molecular reactivity of $\mathbf{M X}$ towards biological systems was explored using condensed molecular descriptors, Fukui functions of electrophilic, nucleophilic and free radical attack. Molecular docking studies for the inhibition of CDK2 and DNA binding were carried out to explore the anticancer potency of MX. The role of charge transfer binding in the interaction of $\mathbf{M X}$ with biological molecules was investigated via studying the ability of $\mathbf{M X}$ to act as a charge transfer acceptor with known donors using NMR spectroscopy. Charge transfer complex formation was confirmed by proton chemical shift and stability constants were measured from the NMR chemical shift data. Stability constants of $\mathbf{M X}$ with donors, phenylene diamine, hexamethyl benzene and pyrene are $4.178,2.527$ and $1.240 \mathrm{M}^{-1}$ respectively.

Keywords: Mitoxantrone; Intramolecular hydrogen bonding; Fukui functions; Molecular modeling; Charge transfer complexes. 


\section{INTRODUCTION}

Mitoxantrone is a symmetric drug composed of tricyclic planar chromophore and two basic side chains. It is an important antineoplastic drug belonging to the anthracycline group. Mitoxantrone is being used for treatment of different types of cancer including myeloid leukemia, breast cancer, lung cancer, and prostate cancer [1-6]. Mitoxantrone is considered a chemotherapeutic drug possessing the potent cytotoxicity of the anthracycline drug family with lower side effects towards cardiotoxicity [5-8]. Anthracycline drugs are known to exert their cytotoxic effects through interaction with DNA resulting in modification of its structure hence inhibition of its replication [9]. Mitoxantrone is known inhibitor to topoisomerase II [10]. Mitoxantrone shows covalent and noncovalent interactions with many biological macromolecules [9]. However, to the best of our knowledge, there is no reported work on the forces of interaction of this important drug with biological systems especially charge transfer forces. In this work, the importance of such force will be investigated through studying the interaction of $\mathbf{M X}$ with known charge transfer agents especially, charge transfer donors.

Although many experimental chemical and physical phenomena of $\mathbf{M X}$ are studied [1116] only few quantum chemical calculations are reported [17-23]. There is a lack of theoretical studies on $\mathbf{M X}$. In the present work, charge transfer formation of $\mathbf{M X}$ with known charge transfer donors were studied to determine the possibility of charge transfer binding of $\mathbf{M X} /$ macromolecules interaction. In addition to that computational geometrical and electronic properties of $\mathbf{M X}$ are investigated. This paper is organized as follows: Section 2 gives details of the computational methods. Section 3 presents the results and 
discussion and is divided into three subsections. This is followed by Section 4, which summarizes main conclusions.

\section{COMPUTATIONAL DETAILS}

All computations were done using G16W suit of programs [24]. Molecular geometry of MX was optimized in the gas phase at DFT B3LYP/6-31+G(d,p) level of theory. Different conformers considering possible intramolecular hydrogen bonding of $\mathbf{M X}$ were computed. A frequency job was performed following each geometry optimization step to confirm a minimum energy structure and to correct energy for zero-point vibrational energy. Fukui functions were calculated using $\mathrm{DMol}^{3}$ module $[25,26]$ employing B3LYP/DND method implemented in Material studio program [27].

\section{EXPERIMENTAL SECTION}

\section{Compounds}

Mitoxantrone was supplied from Aldrich with a purity limit of $97 \%$ and recrystallised twice from dichloromethane. $p$-Phenylenediamine, hexamethylbenzene and pyrene (spectroscopic grade (+99\%)) supplied from Aldrich were used without further purification.

\section{NMR Measurements, General Method}

Nuclear magnetic resonance spectra were recorded in chloroform-d using a BRUKER AC250 machine at $30{ }^{\circ} \mathrm{C}$. NMR data were employed to calculate the equilibrium constant of the MX charge transfer complexes according to the relation described below [28,29]. 
Stock solutions of $\mathbf{M X}$ and other charge transfer donors in $\mathrm{CDCl}_{3}$ were prepared. For NMR scan a series of sample solutions were produced by accurate dilution from the stock solutions keeping constant MX concentration and varying the concentration of the other CT agent. The chemical shift of the $\mathbf{M X}$ bands was measured with reference to the internal standard, TMS. To estimate the uncertainty in the experimental results, all the ${ }^{1} \mathrm{H}$ NMR experiments were measured in triplicates.

\section{RESULTS AND DISCUSSION}

Potential energy surface of molecular conformation based on possibility of intra molecular hydrogen bonding formation, was studied. Five minimum energy conformers, Conf-1, Conf-2, Conf-3 Conf-4 and Conf-5, of MX were computed and displayed in Fig. 1. Conf1 allows four intra-molecular hydrogen bonds while Conf- 2 allows three intra-molecular hydrogen bonds and Conf-3 and Conf-4 allow two and one intra molecular hydrogen bonds, respectively, while Conf-5 has no hydrogen bonds (see Fig. 1). The relative total energies differences are shown in Fig. 1. Conf-1 with four intra molecular hydrogen bonds is the most stable structure separating from Conf-5, with no hydrogen bond, by 48.495 $\mathrm{kcal} / \mathrm{mol}$. Conf- 2 with three hydrogen bonds is the next stable structure with energy difference $14.135 \mathrm{kcal} / \mathrm{mol}$ and Conf-3, with two hydrogen bonds, is separating from Conf1 by $29.017 \mathrm{kcal} / \mathrm{mol}$. Conf- 4 with only one hydrogen bond is separated from the most stable structure, global minimum, by $38.066 \mathrm{kcal} / \mathrm{mol}$. The least stable conformer with no intra molecular hydrogen bonds, Conf-5, has a relative energy of $48.495 \mathrm{kcal} / \mathrm{mol}$. One can 
conclude that each intramolecular hydrogen bond contributes a mean value of 12.124 $\mathrm{kcal} / \mathrm{mol}$ to the stabilization of molecular $\mathbf{M X}$.

Optimized geometry of MX conformers is shown in Fig. 1. All optimized structures, energies and geometries of $\mathbf{M X}$, Conf-1-5, are represented in Fig. 1S-5S in the Supplementary Materials. 

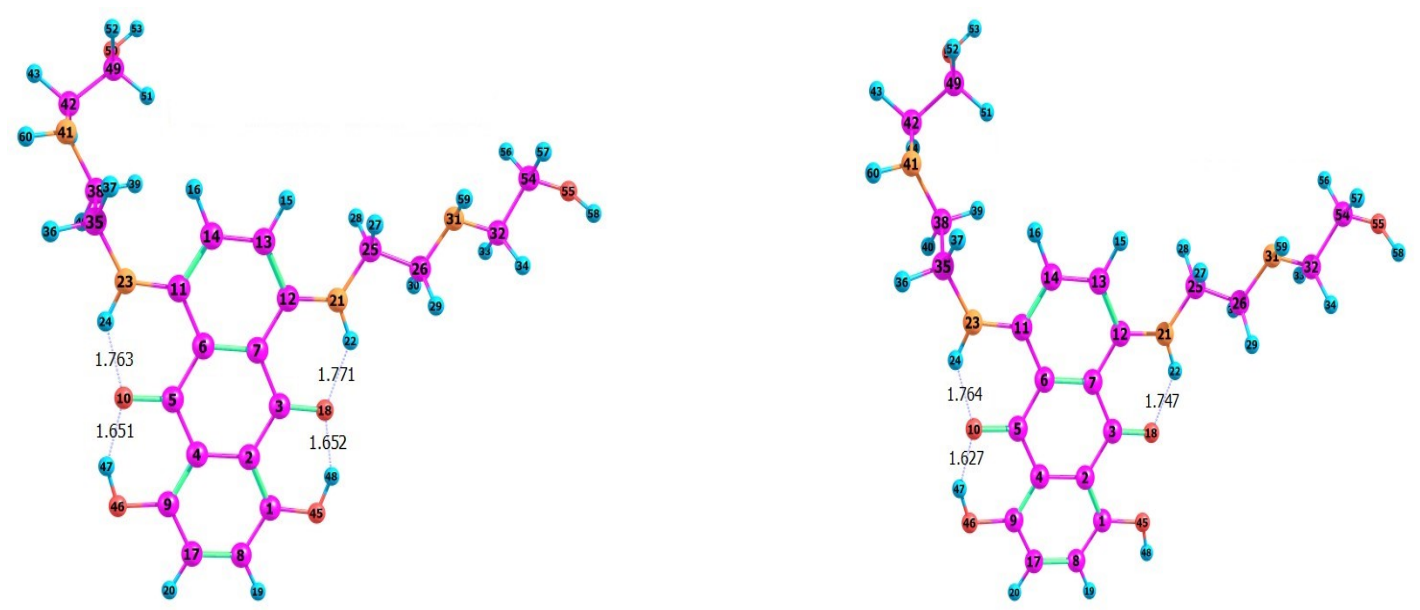

Conf $-1, \Delta \mathrm{E}=0.000 \mathrm{kcal} / \mathrm{mol}$

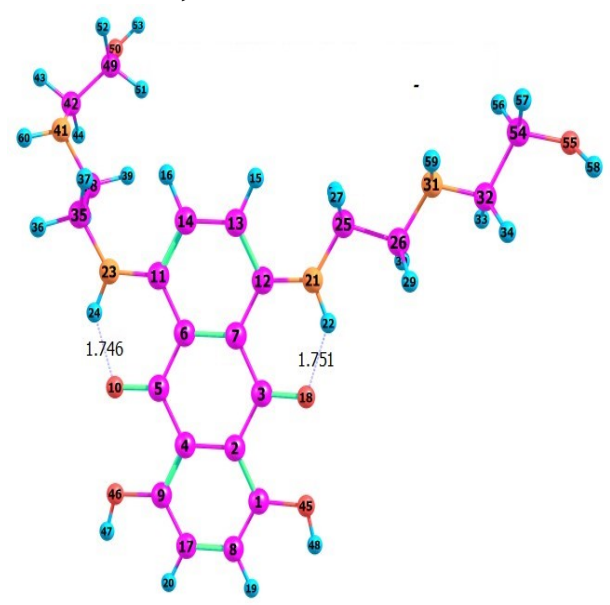

Conf-2, $\Delta \mathrm{E}=14.135 \mathrm{kcal} / \mathrm{mol}$

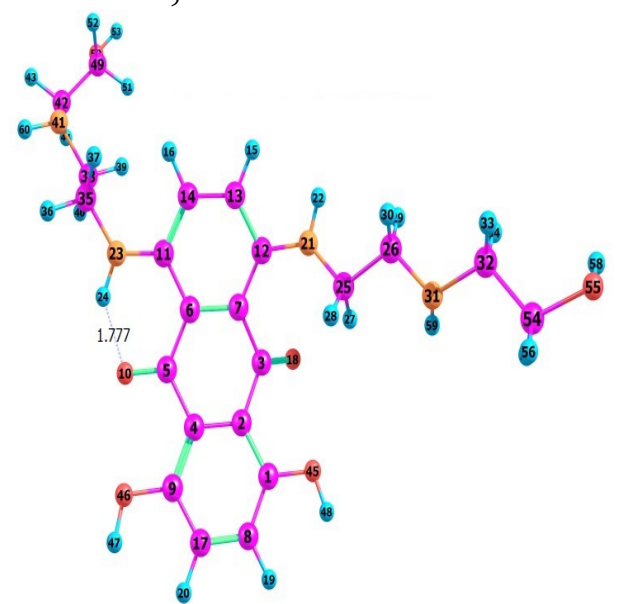

Conf-3, $\Delta \mathrm{E}=29.019 \mathrm{kcal} / \mathrm{mol}$

Conf-4, $\Delta \mathrm{E}=38.066 \mathrm{kcal} / \mathrm{mol}$

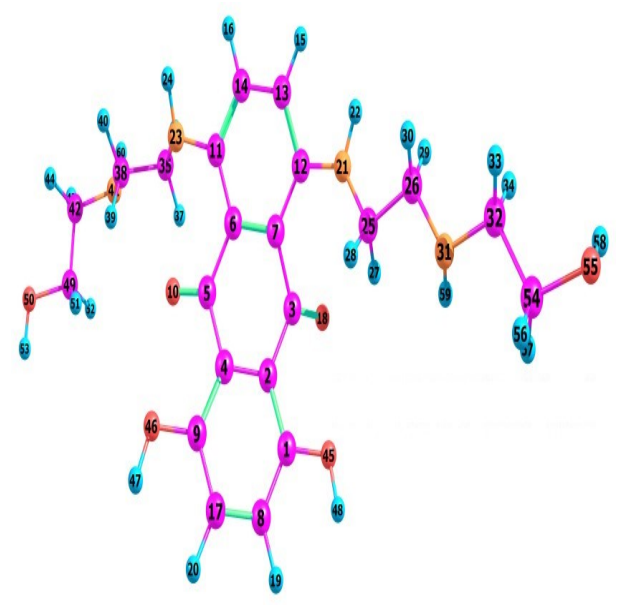

Conf-5, $\Delta \mathrm{E}=48.495 \mathrm{kcal} / \mathrm{mol}$

Fig. 1. Optimized structure of $\mathbf{M X}$ conformers showing atomic numeration, H-bonding and relative energy. 
Natural atomic charges of $\mathbf{M X}$ were computed and displayed in Fig. 2 and additionally presented in Table 1S in the Supplementary Materials. Charges are distributed on the structure atoms and accumulation of charge cannot be detected on any part of the molecule. All H's are positively charged (0.2-0.4) and H's bonded oxygen $(\approx 0.5)$. Hydrogens involved in intramolecular hydrogen bonding have extra positive charge $(\approx 0.043$ for O$\mathrm{H} . . . \mathrm{O}$ and $\approx 0.077$ for $\mathrm{N}-\mathrm{H} . . . \mathrm{O}$ ) more than those not engaged in hydrogen bonding of the side chain. All oxygen and nitrogen atoms are negatively charged $(\mathrm{O}: \approx 0.7-0.8, \mathrm{~N}: \approx 0.6-$ $0.7)$. Carbon atoms have negative charge $(\approx 0.1-0.3)$ except ring carbon atoms attached to oxygen and nitrogen which are positively charged $(\approx 0.2-0.5)$. Another effective way for obtaining information about the distribution of the active sites of a molecule is to calculate its molecular electrostatic potential map. The MEP surface of Mitoxantrone was calculated and displayed in Fig. 3. Negative potential centers are shown on oxygen atoms as expected. Highly positive centers are presented on hydrogen atoms of the hydroxyl groups of the side chains.

One of the most important molecular features of molecules is molecular orbital and its property like atomic contribution coefficients and energy. Frontier orbitals such as highest occupied molecular orbital, HOMO and lowest unoccupied molecular orbital, LUMO are the most important. Molecular orbital surfaces of HOMO and LUMO are shown in Fig. 3. HOMO is delocalized mainly on the ring and oxygen and nitrogen atoms bonded to ring with highest density on carbons 1, 6, 7, 9, 11, 12, 13, 14. C2-C4, C2-C3, C4-C5, C6-C7, $\mathrm{C} 8-\mathrm{C} 17$ and $\mathrm{C} 13-\mathrm{C} 14$ bonds show anti-bonding nature where no electron projection at these regions. Side chains have no contribution to the HOMO. LUMO is being participated highly from $\mathrm{C} 1, \mathrm{C} 8, \mathrm{C} 9, \mathrm{C} 3, \mathrm{C} 5, \mathrm{C} 13$ and $\mathrm{C} 14$. It is clear from Fig. 3 that, the LUMO shows antibonding character over the $\mathrm{C}-\mathrm{H}$ bonds and some $\mathrm{C}-\mathrm{C}$ ring bonds. Side chains also have no contribution to the LUMO. In the ground state the frontier electron density is delocalized on the planar tri-cyclic ring and when some electrons excited to the LUMO the 
electron density will redistributed but still found on the anthraquinone ring. This implies that, the most reactive part of the $\mathbf{M X}$ is the planar ring system which accommodates the frontier orbitals as shown from Fig. 3. Since we are interested in studying the charge transfer properties of MX orbital surfaces of other significant molecular orbitals such as, HOMO-1, HOMO-2 and LUMO+1 also computed and displayed in Fig. 3. As could be expected, HOMO-1 is also located on the tricyclic ring but the HOMO-2 is contributed from one side chain. This suggests the importance of considering these orbitals, especially HOMO-1, and their corresponding eigenvalues upon studying their charge transfer properties.

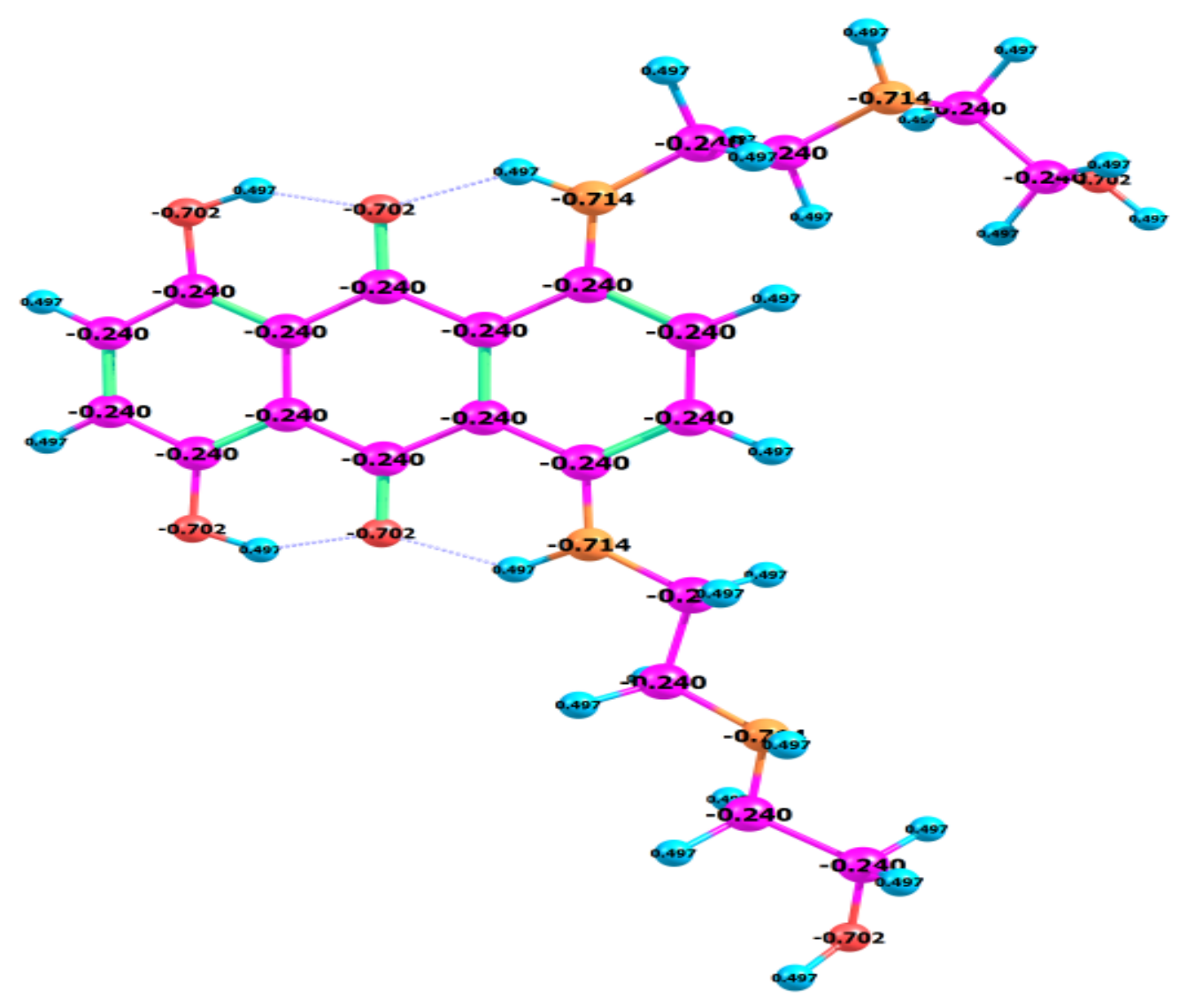

Natural charges

Fig. 2. Calculated natural atomic charges of MX. 

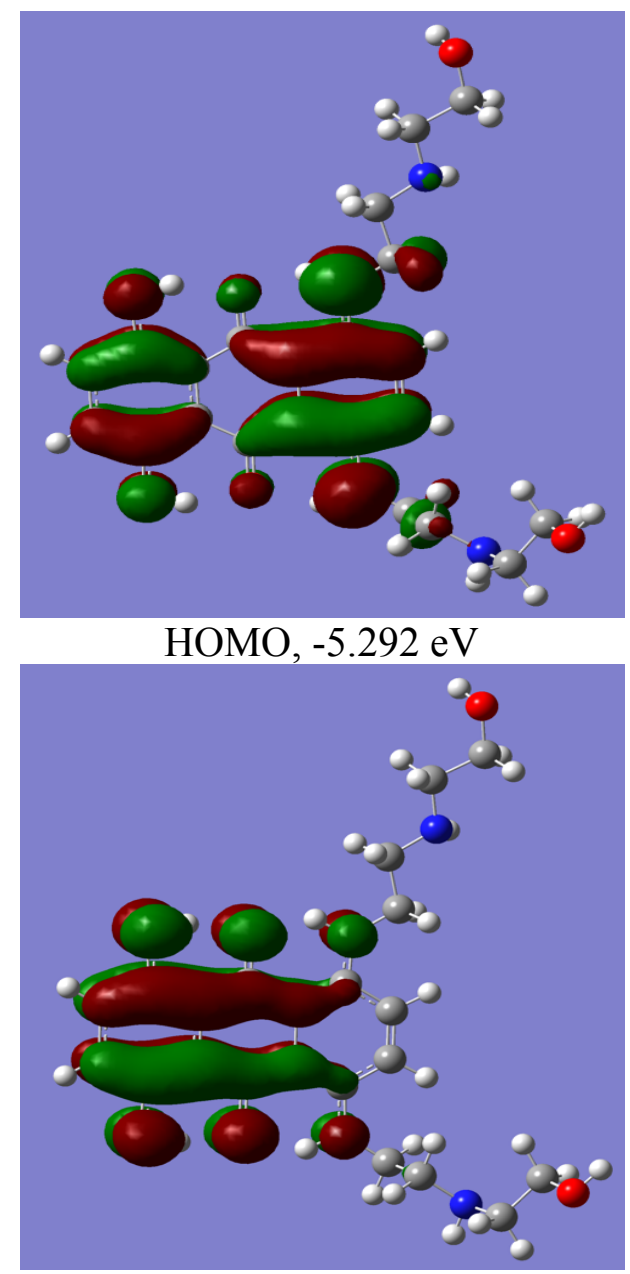

HOMO-1, -6.097 eV

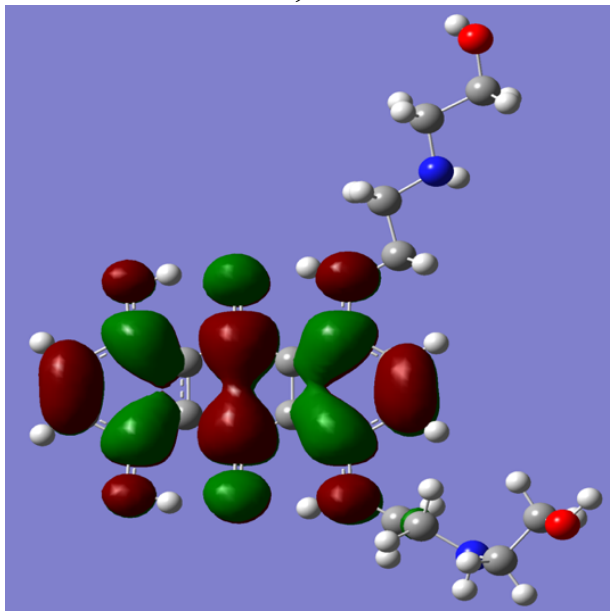

LUMO+1, -1.306 eV

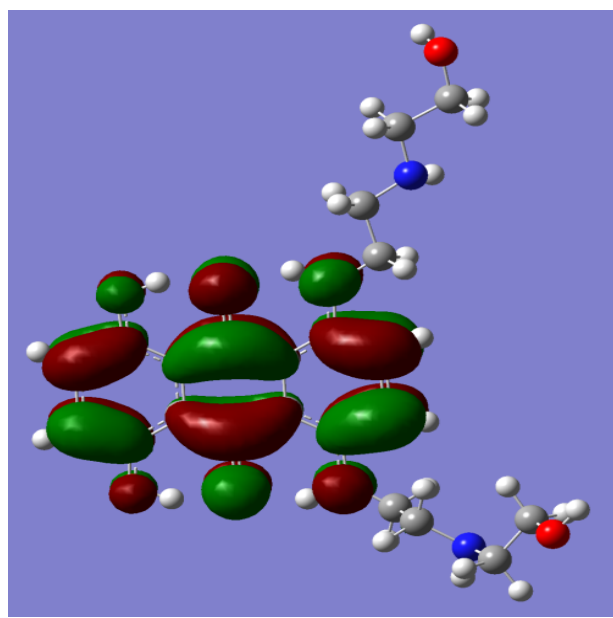

LUMO, -3.045 eV

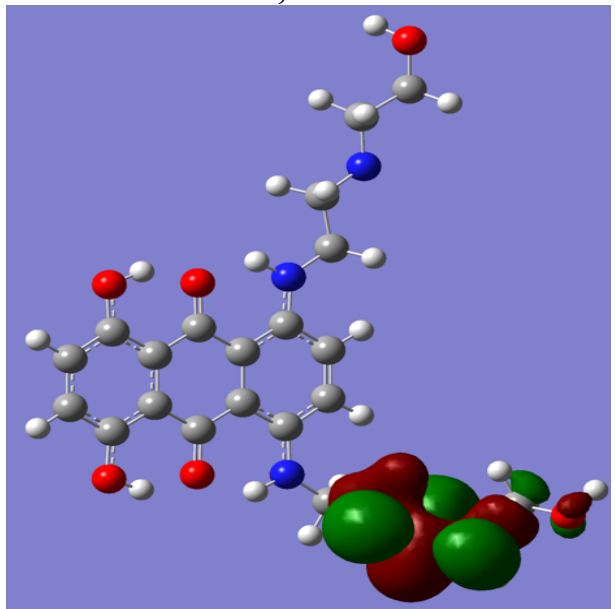

HOMO-2, -6.733 eV

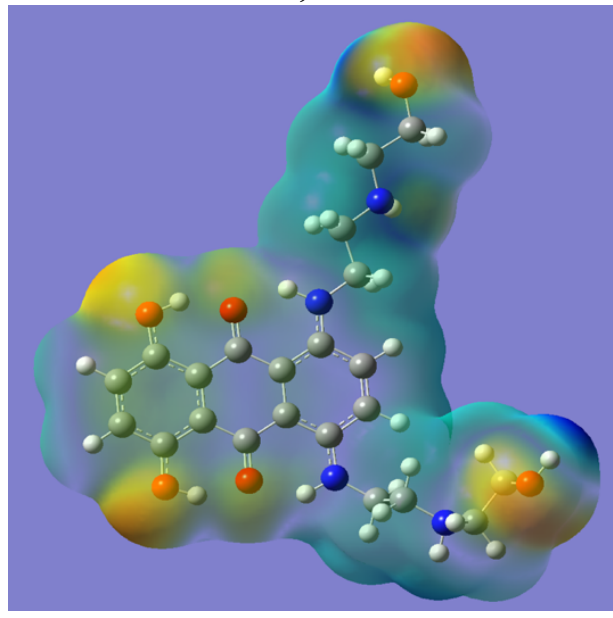

MEP

Fig. 3. Important molecular orbitals surface with their energies and molecular electrostatic potential of $\mathbf{M X}$. 
Fukui function gives the sensitivity of chemical potential of a system to an external perturbation at particular point. It is defined as,

$$
f(\vec{r})=\left(\frac{\partial \rho(\vec{r})}{\partial N}\right)_{v(\vec{r})}=\left(\frac{\delta \mu}{\delta v(\vec{r})}\right)_{N}
$$

Where $\rho(\vec{r})$ is the electron density. In order to describe the reactivity of an atom in a molecule, condensed Fukui functions $\left(f_{k}\right)$ that characterizes the atomic contribution in a molecule towards a certain reaction should be used. For an atom $k$ in a molecule, the $f_{k}$ values are defined as

$$
\begin{aligned}
f_{k}^{+} & =q_{k}(N+1)-q_{k}(N) \\
f_{k}^{-} & =q_{k}(N)-q_{k}(N-1) \\
f_{k}^{o} & =\left[q_{k}(N+1)-q_{k}(N-1)\right] / 2
\end{aligned}
$$

for nucleophilic attack for electrophilic attack for radical attack

We employed the above equations to calculate the value of the condensed Fukui function for every atom for electrophilic, nucleophilic and free radical attacks. By this way, the Fukui function can be used to determine the pin point distribution of the active sites on the MX drug. A qualitative approach of chemical reactivity was introduced Fukui [30] in the form of what we call Frontier Orbital Theory. This theory was demonstrated in the framework of DFT afterwards [31,32]. In a molecular system, the atomic site, which possesses highest condensed Fukui function, favors the higher reactivity. Table 1 shows the condensed Fukui functions as calculated based on Mullikin and Hirshfeld charges for MX. From the results of Table 1, the reactivity for the radical attack was found on $\mathrm{N} 21=\mathrm{N} 23>\mathrm{O} 45=\mathrm{O} 46>\mathrm{C} 14>\mathrm{C} 13>\mathrm{O} 10=\mathrm{O} 18>\mathrm{C} 8=\mathrm{C} 17>\mathrm{C} 1=\mathrm{C} 9>\mathrm{C} 12>\mathrm{C} 3=\mathrm{C} 5$. The most reactive site towards radical attack is nitrogen atoms attached to the ring. For 
nucleophilic attack, the most reactive sites are $\mathrm{O} 18(0.058)$ and $\mathrm{O} 10(0.057)$. The order of reactivity towards nucleophilic attack could be ranked as $\mathrm{O} 18>\mathrm{O} 10>\mathrm{C} 14>\mathrm{C} 13>$ $\mathrm{C} 8=\mathrm{C} 17>\mathrm{C} 3=\mathrm{C} 5>\mathrm{C} 5>\mathrm{O} 45=\mathrm{O} 46>\mathrm{N} 21=\mathrm{N} 23>\mathrm{C} 1=\mathrm{C} 11=\mathrm{C} 12$. On the other hand, for electrophilic attack, the most reactive site is N21(0.066), N23(0.065), O45(0.051) and O46 (0.050). The reactivity order towards electrophilic attack could be ranked as N21 > N23 > $\mathrm{O} 45>\mathrm{O} 46>\mathrm{C} 7>\mathrm{C} 6=\mathrm{C} 8=\mathrm{C} 17>\mathrm{C} 1>\mathrm{C} 9>\mathrm{C} 11>\mathrm{C} 12=\mathrm{C} 14>\mathrm{C} 13$. Another conclusion could be withdrawn from the Table 1 is that $\mathbf{M X}$ is more likely to act as an electophile than being as a nucleophile. This finding is also, confirmed by the NMR charge transfer complexes interaction that shows $\mathbf{M X}$ acts as an electron acceptor with known charge transfer donors. 
Table 1. Condensed Fukui Functions $\left(f_{k}^{0}\right)\left(f_{k}^{+}\right)$and $\left(f_{k}^{-}\right)$indices of $\mathbf{M X}$

\begin{tabular}{|c|c|c|c|c|c|c|}
\hline & \multicolumn{2}{|c|}{$\begin{array}{c}\text { Fukui Indices for radical } \\
\text { attack } \\
f_{k}^{0}\end{array}$} & \multicolumn{2}{|c|}{$\begin{array}{c}\text { Fukui Indices for nucleophilic } \\
\text { attack } \\
f_{k}^{+}\end{array}$} & \multicolumn{2}{|c|}{$\begin{array}{l}\text { Fukui Indices for electrophilic } \\
\text { attack } \\
\qquad f_{\bar{k}}^{-} \\
\end{array}$} \\
\hline & Mulliken & Hirshfeld & Mulliken & Hirshfeld & Mulliken & Hirshffeld \\
\hline$C$ C(1) & 0.024 & 0.031 & 0.022 & 0.028 & 0.027 & 0.034 \\
\hline $\mathrm{C}(\mathrm{2})$ & 0.007 & 0.010 & 0.006 & 0.012 & 0.007 & 0.009 \\
\hline C ( 3) & 0.030 & 0.028 & 0.046 & 0.043 & 0.015 & 0.013 \\
\hline C( (4) & 0.007 & 0.010 & 0.006 & 0.012 & 0.008 & 0.009 \\
\hline C ( 5) & 0.03 & 0.028 & 0.046 & 0.043 & 0.015 & 0.012 \\
\hline$C(6)$ & 0.018 & 0.023 & 0.006 & 0.011 & 0.030 & 0.035 \\
\hline$C(7)$ & 0.018 & 0.024 & 0.006 & 0.011 & 0.030 & 0.036 \\
\hline C ( 8) & 0.027 & 0.040 & 0.032 & 0.046 & 0.022 & 0.035 \\
\hline $\mathrm{C}(9)$ & 0.024 & 0.031 & 0.022 & 0.028 & 0.026 & 0.033 \\
\hline$O(10)$ & 0.040 & 0.041 & 0.056 & 0.057 & 0.023 & 0.025 \\
\hline $\mathrm{C}(11)$ & 0.021 & 0.030 & 0.022 & 0.028 & 0.020 & 0.032 \\
\hline$C(12)$ & 0.021 & 0.029 & 0.021 & 0.028 & 0.020 & 0.031 \\
\hline C (13) & 0.031 & 0.042 & 0.042 & 0.054 & 0.020 & 0.030 \\
\hline C (14) & 0.031 & 0.043 & 0.042 & 0.055 & 0.021 & 0.031 \\
\hline $\mathrm{H}(15)$ & 0.044 & 0.023 & 0.047 & 0.026 & 0.040 & 0.020 \\
\hline $\mathrm{H}(16)$ & 0.043 & 0.023 & 0.047 & 0.026 & 0.040 & 0.020 \\
\hline$C(17)$ & 0.026 & 0.040 & 0.032 & 0.046 & 0.021 & 0.035 \\
\hline$O(18)$ & 0.04 & 0.041 & 0.056 & 0.058 & 0.024 & 0.025 \\
\hline H (19) & 0.045 & 0.024 & 0.047 & 0.026 & 0.042 & 0.022 \\
\hline $\mathrm{H}(20)$ & 0.045 & 0.024 & 0.048 & 0.026 & 0.042 & 0.022 \\
\hline $\mathrm{N}(21)$ & 0.049 & 0.049 & 0.03 & 0.032 & 0.068 & 0.066 \\
\hline $\mathrm{H}(22)$ & 0.018 & 0.015 & 0.015 & 0.012 & 0.022 & 0.019 \\
\hline $\mathrm{N}(23)$ & 0.049 & 0.049 & 0.03 & 0.032 & 0.068 & 0.065 \\
\hline H (24) & 0.019 & 0.016 & 0.016 & 0.012 & 0.022 & 0.019 \\
\hline $\mathrm{C}(25)$ & 0.025 & 0.008 & 0.022 & 0.006 & 0.027 & 0.011 \\
\hline $\mathrm{C}(26)$ & 0.003 & 0.002 & 0.002 & 0.002 & 0.004 & 0.002 \\
\hline $\mathrm{H}(27)$ & 0.029 & 0.015 & 0.024 & 0.012 & 0.033 & 0.018 \\
\hline $\mathrm{H}(28)$ & 0.028 & 0.015 & 0.023 & 0.012 & 0.032 & 0.017 \\
\hline $\mathrm{H}(29)$ & 0.008 & 0.003 & 0.007 & 0.002 & 0.01 & 0.004 \\
\hline $\mathrm{H}(30)$ & 0.008 & 0.003 & 0.007 & 0.003 & 0.01 & 0.004 \\
\hline $\mathrm{N}(31)$ & 0.002 & 0.005 & 0.001 & 0.004 & 0.002 & 0.005 \\
\hline $\mathrm{C}(32)$ & 0.009 & 0.003 & 0.008 & 0.002 & -0.01 & 0.003 \\
\hline $\mathrm{H}(33)$ & 0.001 & 0.001 & 0.001 & 0.001 & 0.002 & 0.001 \\
\hline H (34) & 0.013 & 0.006 & 0.012 & 0.005 & 0.014 & 0.006 \\
\hline C ( 35$)$ & 0.021 & 0.008 & 0.019 & 0.006 & 0.023 & 0.010 \\
\hline $\mathrm{H}(36)$ & 0.030 & 0.015 & 0.027 & 0.014 & 0.033 & 0.016 \\
\hline $\mathrm{H}(37)$ & 0.022 & 0.012 & 0.019 & 0.010 & 0.026 & 0.014 \\
\hline C (38) & 0.000 & 0.004 & 0.001 & 0.003 & 0.001 & 0.006 \\
\hline H (39) & 0.001 & 0.001 & 0.003 & 0.000 & 0.004 & 0.002 \\
\hline
\end{tabular}




\begin{tabular}{|c|l|l|l|l|l|l|}
\hline $\mathrm{H}(40)$ & 0.010 & 0.004 & 0.008 & 0.003 & 0.011 & 0.005 \\
\hline $\mathrm{N}(41)$ & 0.005 & 0.008 & 0.003 & 0.006 & 0.006 & 0.009 \\
\hline $\mathrm{C}(42)$ & 0.007 & 0.004 & 0.006 & 0.004 & 0.008 & 0.005 \\
\hline $\mathrm{H}(43)$ & 0.018 & 0.009 & 0.017 & 0.009 & 0.019 & 0.010 \\
\hline $\mathrm{H}(44)$ & 0.007 & 0.003 & 0.006 & 0.003 & 0.008 & 0.004 \\
\hline $\mathrm{O}(45)$ & 0.048 & 0.045 & 0.042 & 0.039 & 0.054 & 0.051 \\
\hline $\mathrm{O}(46)$ & 0.048 & 0.045 & 0.042 & 0.039 & 0.054 & 0.050 \\
\hline $\mathrm{H}(47)$ & 0.015 & 0.013 & 0.015 & 0.013 & 0.014 & 0.013 \\
\hline $\mathrm{H}(48)$ & 0.015 & 0.013 & 0.015 & 0.013 & 0.015 & 0.013 \\
\hline $\mathrm{C}(49)$ & 0.001 & 0.000 & 0.002 & 0.000 & 0.001 & 0.001 \\
\hline $\mathrm{O}(50)$ & 0.007 & 0.007 & 0.006 & 0.007 & 0.007 & 0.008 \\
\hline $\mathrm{H}(51)$ & 0.008 & 0.003 & 0.009 & 0.003 & 0.008 & 0.003 \\
\hline $\mathrm{H}(52)$ & 0.006 & 0.002 & 0.006 & 0.002 & 0.007 & 0.003 \\
\hline $\mathrm{H}(53)$ & 0.007 & 0.005 & 0.006 & 0.005 & 0.007 & 0.006 \\
\hline $\mathrm{C}(54)$ & 0.002 & 0.002 & 0.002 & 0.002 & 0.001 & 0.002 \\
\hline $\mathrm{O}(55)$ & 0.006 & 0.007 & 0.005 & 0.007 & 0.006 & 0.007 \\
\hline $\mathrm{H}(56)$ & 0.001 & 0.001 & 0.001 & 0.001 & 0.001 & 0.001 \\
\hline
\end{tabular}




\section{Molecular docking and binding energy calculations}

Mitoxantrone anticancer drug is known to do its anticancer activity via DNA intercalation, inhibition of transferase human CDK2 and inhibition of topoisomerase II [33-36]. Accordingly, we docked it into the crystal structures of protein kinase PknB and DNA employing intercalation interactions. The coordinates for the protein structure and DNA was obtained from the RCSB Protein Data Bank (PDB; 2FUM (Resolution: $2.89 \AA$ ) [37] and 1G3X, (Resolution: $2.7 \AA$ ) [38]. Protein Structures were prepared using Discovery Studio (DS 2.0) software package [39]. The invalid or missing residues were added and the structures were aligned using the protein structure alignment module. Hydrogen atoms were added and the structure was minimized using CHARMM force field to relax the backbone and to remove any clashes. Mitoxantrone was optimized by DFT method (B3LYB/6-31+G(d)) using G16 software. C-Docker with its default parameters was used to dock the MX into protein kinase PknB and DNA active sites. Fig. 4 shows binding model of mitoxantrone with protein kinase PknB transferase and DNA. The results are summarized in Table 2 along with our reported results of the structurally related AQ4, $\mathrm{AQ} 4 \mathrm{H}$ and 1,4-DAAQ for comparison [40]. One can see that $\mathbf{M X}$ is more potent drug than other anthraquinone drugs. The interaction of $\mathbf{M X}$ with CDK2 (interaction energy, 69.747) is stronger than AQ4, AQ4H and 1,4-DAAQ. For DNA intercalation binding MX is the most binder (interaction energy, -73.051) as can be seen from Table 2 .

Table 2. C-Docker interaction energy and binding energy of MX and AQ4, AQ4H and 1,4-DAAQ with CDK2 enzyme and DNA

\begin{tabular}{|l|c|c|}
\hline System & binding energy & interaction energy \\
\hline MX/CDK2 & -45.484 & -69.747 \\
\hline AQ4/CDK2 & -38.880 & -58.077 \\
\hline AQ4H/CDK2 & -33.340 & -52.914 \\
\hline 1,4-DAAQ/CDK2 & -20.632 & -30.751 \\
\hline MX/DNA (intercalation & -62.847 & -73.051 \\
\hline AQ4/DNA (intercalation) & -53.665 & -54.189 \\
\hline AQ4H/DNA (intercalation) & -58.357 & -57.331 \\
\hline 1,4-DAAQ/DNA (intercalation) & -15.909 & -26.080 \\
\hline
\end{tabular}


Docking of MX in CDK2 active site revealed the formation of two H-bonds. One between MX:O50 and GLY97:HN of distance $2.182 \AA$ and DHA angle of $129.8^{\circ}$. The second, more stronger, H-bond between MX:O55 and residue LYS140 of distance $1.858 \AA$ and DHA angle of $125.4^{\circ}$ (Fig. 4). Docking of $\mathbf{M X}$ in DNA revealed the formation of two H-bonds. One between MX:H59 and Cytocine 621:O2 of distance $2.120 \AA$ and DHA angle of $159.9^{\circ}$. The second, H-bond between MX:H60 and residue Thymine 619:O3 of distance $2.212 \AA$ and DHA angle of $163.7^{\circ}$ (Fig. 4). This binding pattern agrees with that reported elsewhere $[41,42]$. 


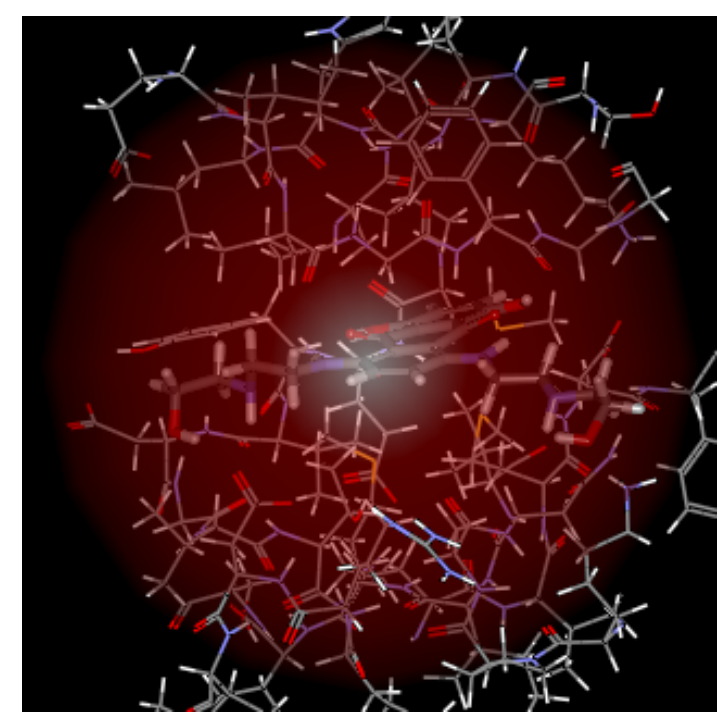

a) $\mathrm{MX}$ in the active site of CDK2

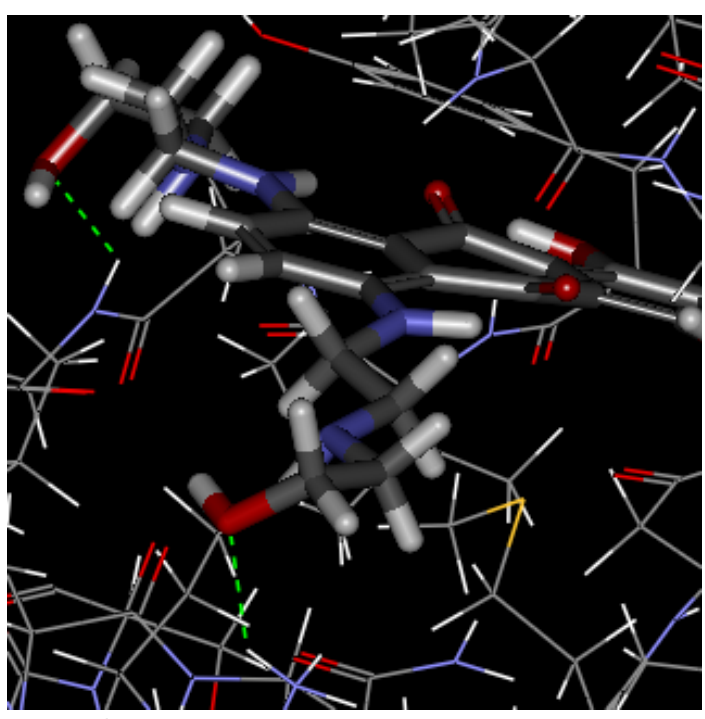

c) Close interaction of $\mathrm{MX}$ with CDK2

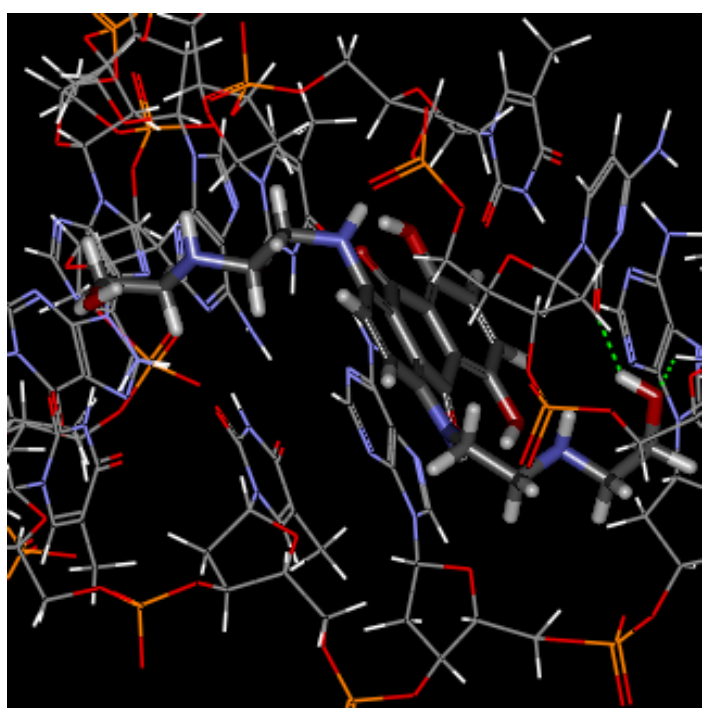

e) Interaction of $\mathbf{M X}$ with DNA

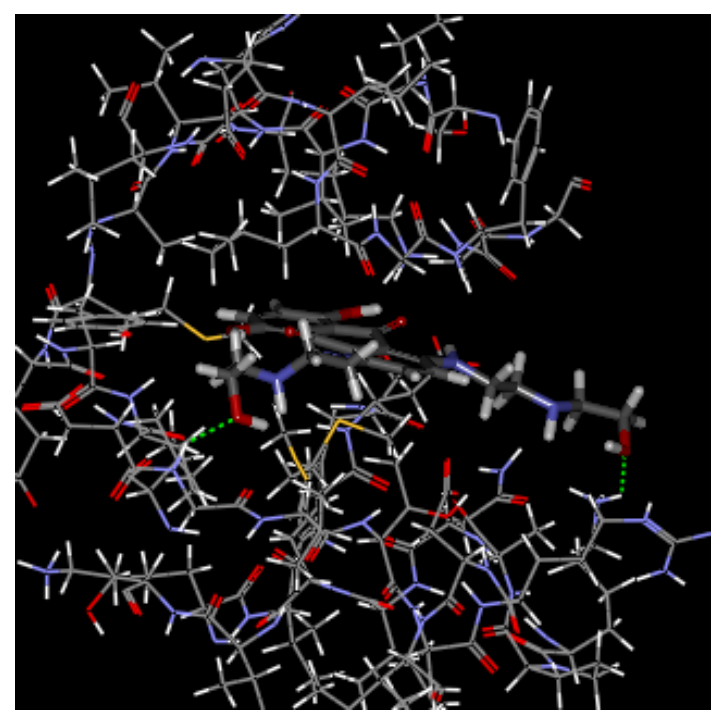

b) Interaction of $\mathbf{M X}$ with $\mathrm{CDK} 2$

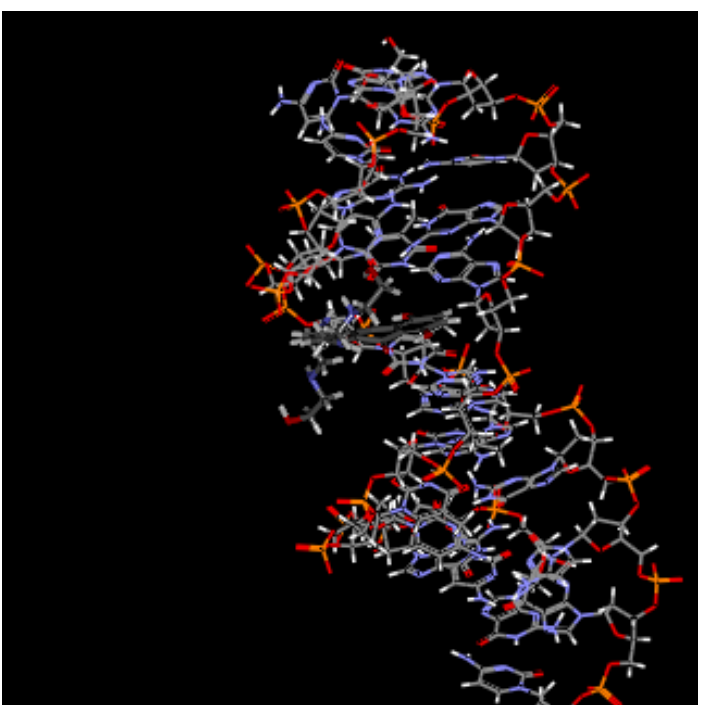

d) $\mathrm{MX} / \mathrm{DNA}$ intercalation complex

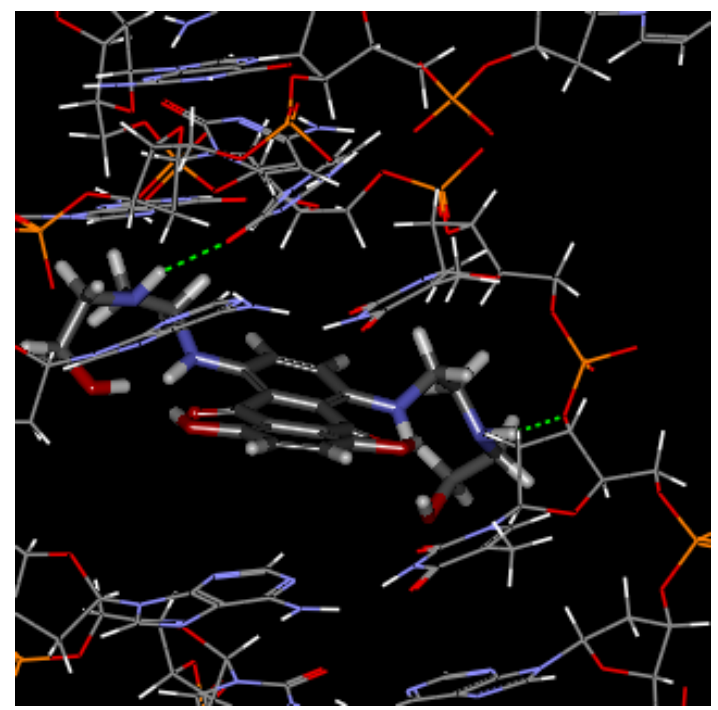

f) Interaction of $\mathbf{M X}$ with DNA

Fig. 4. 3D nonbonding interactions of $\mathbf{M X}$ with ATP active site of CDK2 and DNA. a) showing the $\mathbf{M X}$ in the active site sphere of CDK2, b) hydrogen bonding interaction 
between MX and CDK2 active site, c) showing a focused view of hydrogen bonding interaction between MX and CDK2 active site, d) showing MX/DNA intercalation complex, d) and f) showing the hydrogen bonding interaction between MX and DNA bases. 


\subsubsection{Charge-Transfer Complexes of $M X$ :}

To understand the mechanism of interaction between $\mathbf{M X}$ and biological systems and to find out, particularly, the role of charge transfer forces in such interaction, we investigate the ability of $\mathbf{M X}$ to act as an electron acceptor with known charge transfer (CT) donors. For this study p-phenylenediamine (PDA) [43,44], pyrene, (PY) [45-49] and hexamethylbenzene, (HMB) [50-52] were selected as electron donors. Spectroscopic tools as UV-VIS absorption spectroscopy, fluorescence emission spectroscopy and NMR spectroscopy usually used to study CT complexes. Of which the oldest way is the UV-VIS absorption spectroscopy. Comparing to UV-VIS absorption spectroscopy and fluorescence emission spectroscopy, NMR tool is the most sensitive/accurate. NMR has been successfully used to evaluate equilibrium constants in hydrogen-bonding systems [53-55] and later in CT systems $[56,57]$ since the two types of equilibria are formally the same. Further, NMR is extremely sensitive to small changes in the electronic environment of a magnetic nucleus, and a study of the appropriate NMR parameters may be another means of obtaining structural information about molecular complexes.

${ }^{1} \mathrm{H}$ NMR spectra for the complexes of Mitoxantrone with CT donors used were determined in $\mathrm{CDCl}_{3} .{ }^{1} \mathrm{H}$ NMR spectra of different mixtures of PY and $\mathbf{M X}$ are represented in Figs. 57. The protons of the acceptor (MX) in all complexes, are shifted upfield $[58,59]$. The experimental proton chemical shift differences between the complexed and the free $\mathbf{M X}$ were measured three times to minimize the experimental error. The uncertainty (standard deviation) in the chemical shift measurement was determined and shown in Fig. (6S) in the Supplementary Materials. 

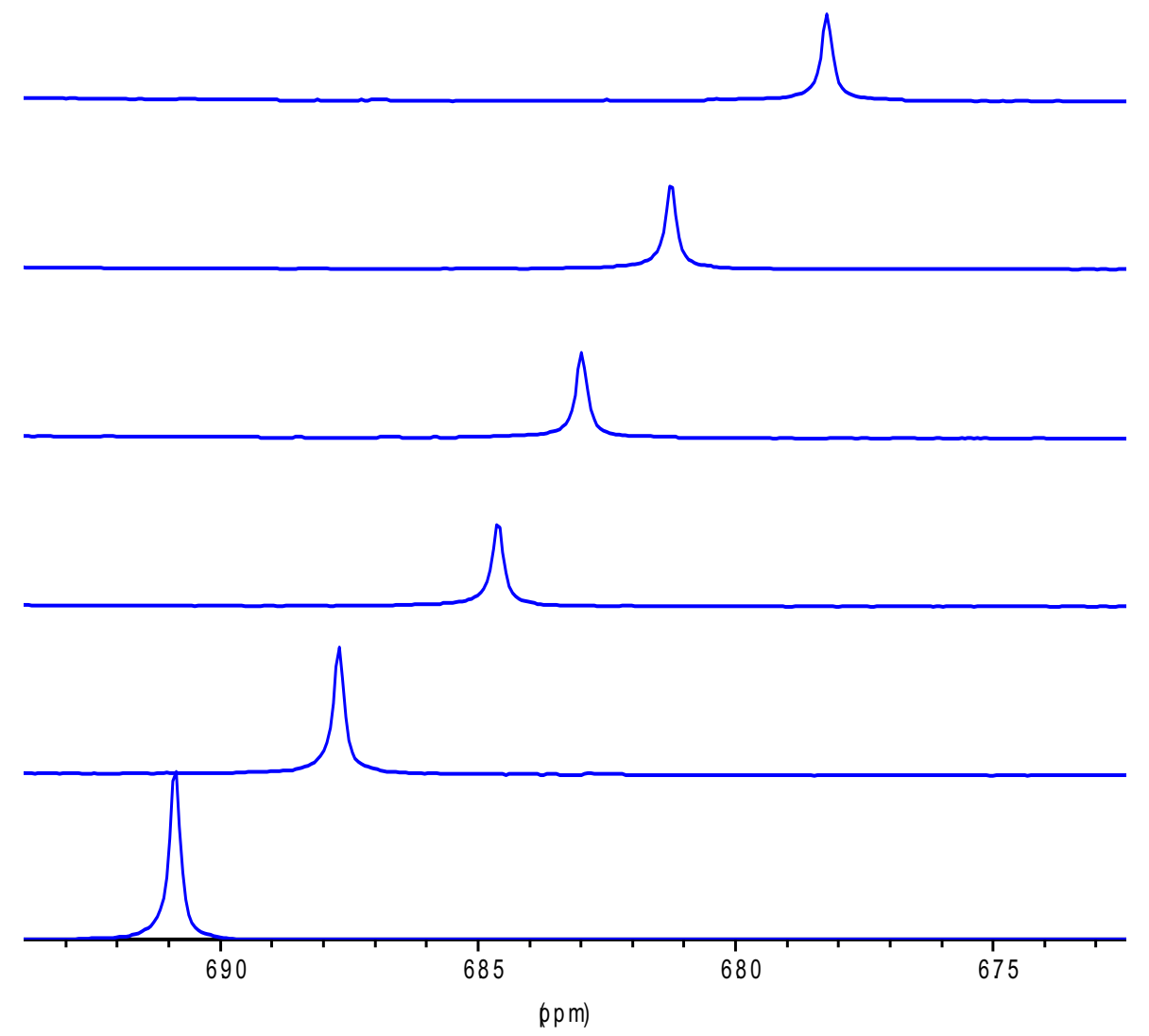

Fig. 5. ${ }^{1} \mathrm{H}$ NMR spectrum of $\mathrm{H}(2)$ of $\mathbf{M X}$ in its mixtures with PY; concentration of $\mathbf{M X}$ is $6.031 \times 10^{-3} \mathrm{M}$ and concentrations of PY from bottom to top are: $0.0,0.0250,0.0512$, $0.0637,0.0761$, and $0.1016 \mathrm{M}$. 

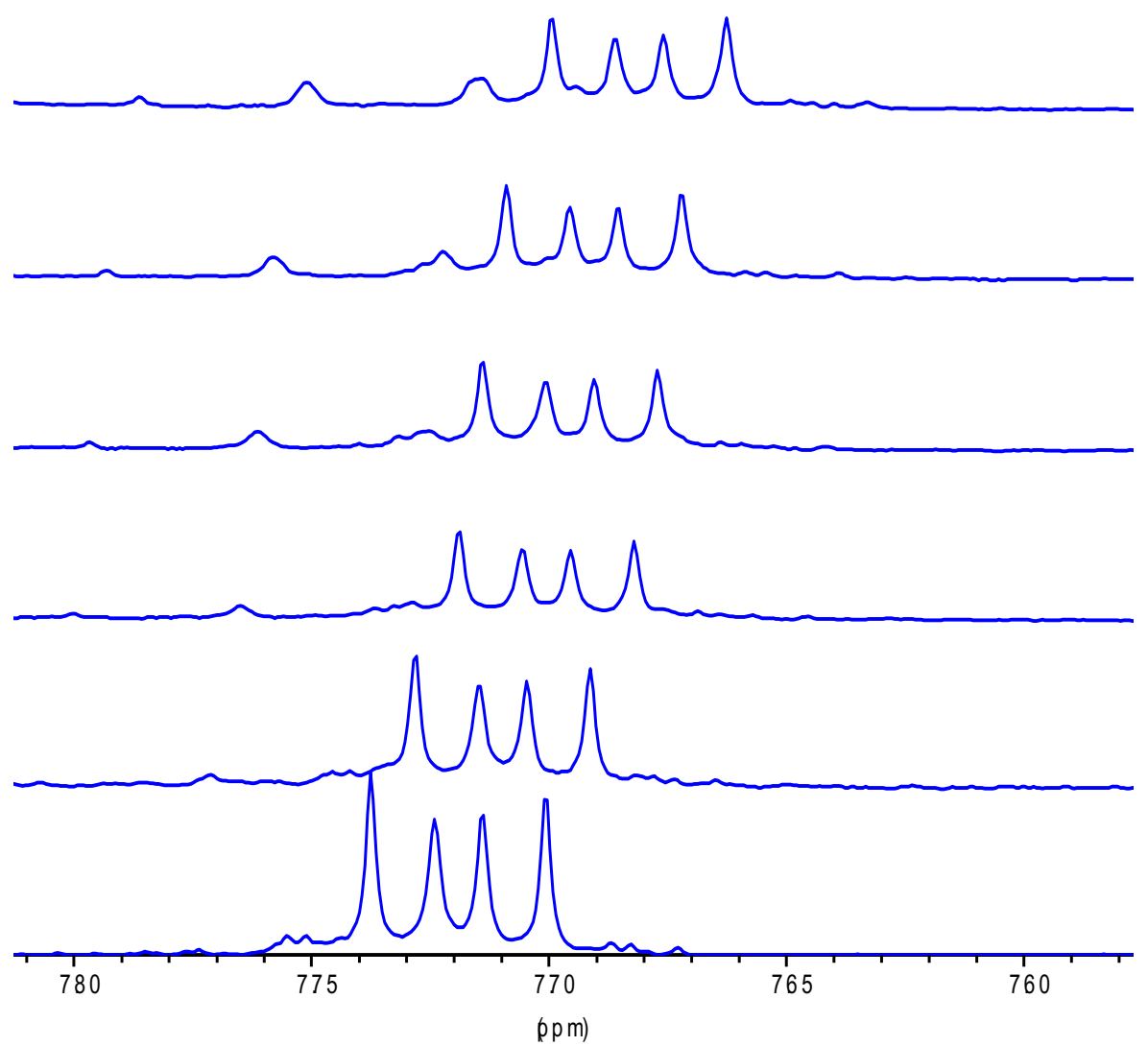

Fig. 6. ${ }^{1} \mathrm{H}$ NMR spectrum of $\mathrm{H}(6)$ of $\mathbf{M X}$ in its mixtures with PY; concentration of $\mathbf{M X}$ is $6.031 \times 10^{-3} \mathrm{M}$ and concentrations of PY from bottom to top are: $0.0,0.0250$, $0.0512,0.0637,0.0761$, and $0.1016 \mathrm{M}$. 

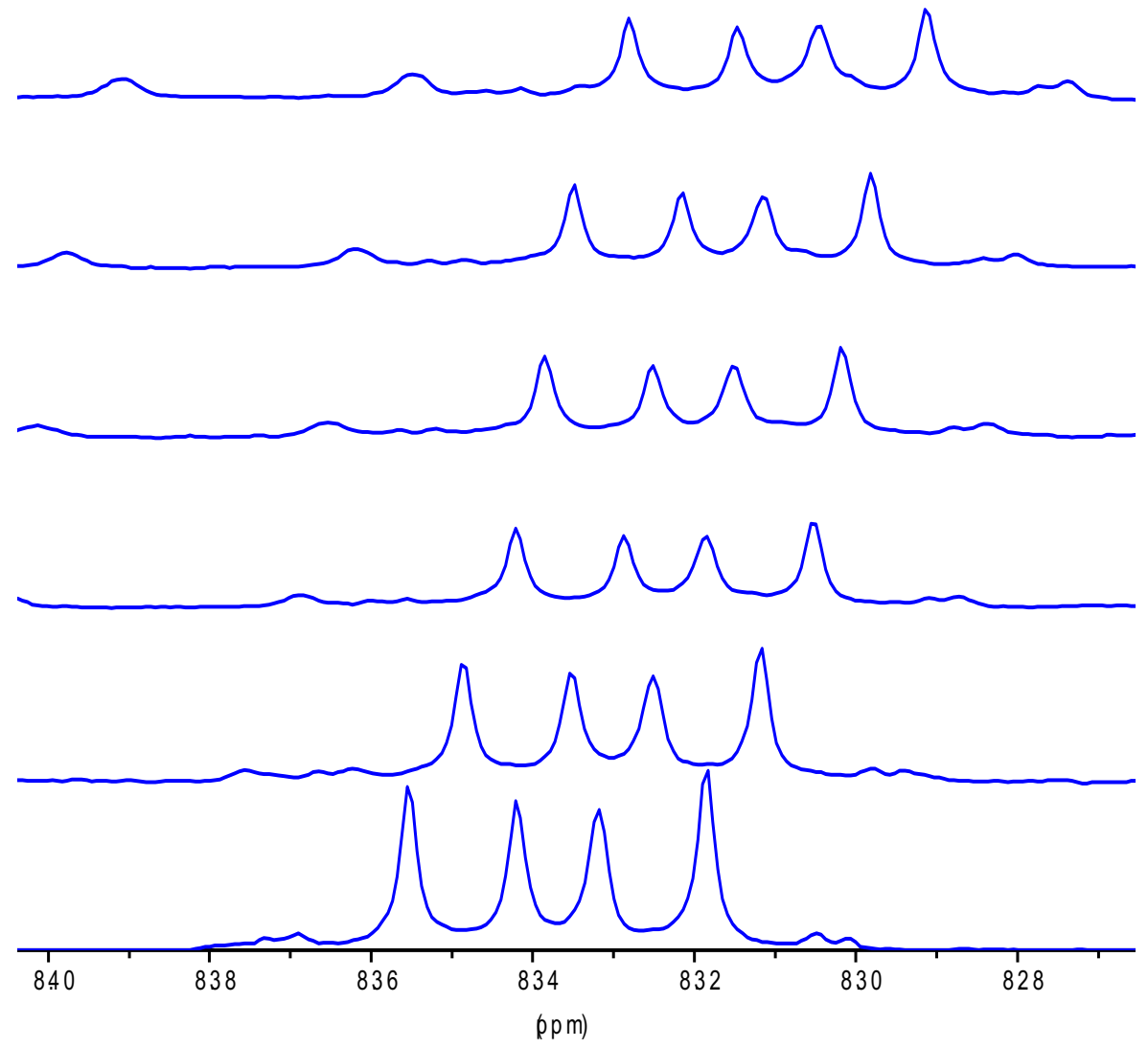

Fig. 7. ${ }^{1} \mathrm{H}$ NMR spectrum of $\mathrm{H}(5)$ of $\mathbf{M X}$ in its mixtures with PY; concentration of $\mathbf{M X}$ is $6.031 \times 10^{-3} \mathrm{M}$ and concentrations of PY from bottom to top are: $0.0,0.0250$, $0.0512,0.0637,0.0761$, and $0.1016 \mathrm{M}$. 
Table 3 shows the maximum chemical shift differences of different protons of $\mathbf{M X}$ in their charge-transfer complexes with CT donors. Figure (6S), in the Supplementary Materials, shows how different acceptor-protons shifts are changed with the donor concentration in the system PDA/1,4-DAAQ.

Table 3. Maximum upfield chemical shift differences (Hz) of different protons ${ }^{\mathrm{a}}$ of $\mathbf{M X}$ in their mixtures with CT-donors and measured properties of their charge-transfer complexes.

\begin{tabular}{|l|l|l|l|l|l|l|c|c|c|}
\hline System & $\mathrm{H}(2)$ & $\mathrm{H}(3)$ & $\mathrm{H}(5)$ & $\mathrm{H}(6)$ & $\mathrm{H}(7)$ & $\mathrm{H}(8)$ & $\begin{array}{c}\Delta_{2, \max .} \\
(\mathrm{Hz})\end{array}$ & $\mathrm{K}_{11}\left(\mathrm{M}^{-1}\right)$ & $\Delta_{11}(\mathrm{~Hz})$ \\
\hline PDA/MX & -3.929 & -3.929 & -0.024 & -0.854 & -0.854 & -0.024 & -3.929 & $4.178 \pm 1.10$ & $-14.31 \pm 4.45$ \\
\hline PY/MX & -39.66 & -39.66 & -8.60 & -12.04 & -12.04 & -8.60 & -39.66 & $1.240 \pm 0.31$ & $-326.42 \pm 80.21$ \\
\hline HMB/MX & -12.08 & -12.08 & -4.18 & -5.31 & -5.31 & -4.18 & -12.08 & $2.527 \pm 0.68$ & $-63.21 \pm 8.79$ \\
\hline
\end{tabular}

a See Fig. 8 for proton numeration.

\section{Association Constant Determination}

NMR chemical shift data can be used for the determination of association constants of equilibria involving fast reactions could be applied to CT complex formation. There is a number of chemical-shift determinations from association constants for typical organic CT complexes have been made [57,60-66].

Protons equivalent to $\mathrm{H}(2)$ were chosen for equilibrium constant determinations because it is a singlet band in MX and clear enough to follow. The equation below $[28,29]$ is used to determine the association constant of the non-covalent complex formed. In the below equation, $\Delta$ is the chemical shift difference between that of HMB/MX mixture $(\mathrm{H}(2)$ nucleus) and the chemical shift of the same nucleus in the pure acceptor (MX). $\Delta_{11}$ is the difference of chemical shift between the pure complex and the pure acceptor (MX). $[\mathrm{L}]$ is 
the varied donor $(\mathrm{HMB})$ concentration and $\mathrm{K}_{11}$ is the stability constant. A typical plot of $1 / \Delta$ vs $1 / \mathrm{L}$, for the system $\mathrm{HMB} / \mathbf{M X}$ using this equation below is shown in Fig. (8). The shift in pure complex, $\Delta_{11}$, and the association constant, $K_{11}$, were calculated from the intercept and the intercept/slope ratio respectively.

$$
\frac{1}{\Delta}=\frac{1}{\Delta_{11} K_{11}[L]}+\frac{1}{\Delta_{11}}
$$

The maximum observed shifts for $\mathrm{H}(2)$ in the acceptor, the determined association constant and the shifts of $\mathrm{H}(2)$ of the acceptor in the pure complex are given in Table (3). The observed chemical shift is a direct effect of molecular complexation. The major advantage of the NMR method compared with UV-VIS spectra is that complexes can be studied that have no separate CT band in the visible or ultraviolet spectrum, or where the CT band is buried beneath the spectrum of one of the components. The stability constant of the formed CT molecular complexes of $\mathbf{M X}$ with charge transfer donors are 4.178, 2.527 and $1.240 \mathrm{M}^{-1}$ for PDA/MX, HMB/MX and PY/MX respectively. These values are comparable with our previous reported results for anthraquinones with CT donors [28,29]. PDA/MX is the most stable complex reflecting the largest interaction between $\mathbf{M X}$ and the strongest donor PDA.

\section{The Chemical Shift of Pure Complex}

A consideration of the chemical shifts of pure complexes in Table (3) shows first, that all complex shifts are to higher field, and second, that larger shifts are associated with lower equilibrium constants. These results can be rationalized by a consideration of the possible effects on the acceptor proton resonance position that the donor might have. These effects 
are: 1. Transfer of charge from donor to acceptor, 2. Effect on acceptor protons of ring currents in the donor, 3. Electric field effects of the donor on acceptor protons, 4. Modification of ring currents in acceptor, if present, by interaction with the donor, 5 . Alteration of the paramagnetic contribution to the acceptor protons shifts. Effect 1 would result in an upfield shift if the electron density in the acceptor molecule were increased by transfer of charge from the donor. All theories of $\pi$ - molecular complexes agree, however, that the amount of such charge transfer is very small. Using the results of Fraenkel. et al., [67] which indicate that the shielding of a $\sigma$-proton is increased by approximately 10 p.p.m. for a one $\pi$-electron increase on the adjacent carbon, one calculates that there would have to be a "transfer" of 0.14 electron from donor to acceptor to explain the maximum shift. Further, if effect 1 were the cause of the upfield shift, this shift should go to even higher fields as complexes become stronger. Such is not the case, and therefore effect 1 is ruled out.

Effect 2 would also give an upfield shift. This effect is certainly of importance and may be the principal cause of the upfield shift of all complexes. The upfield shifts are approximately the same order as those discussed by Schneider [68].

Effect 3 would be very small since the donor molecules have very small dipole moments. Effect 4 can be ruled out because, regardless of the way in which the acceptor ring currents were modified by interactions with the donor, the effect would be expected to increase as the complex became stronger. This effect, like effect 1 , is unlikely to be important because complex formation is only a small perturbation on the ground state of the acceptor. Effect 5 would predict a downfield shift of the acceptor protons. A combination of this effect with effect 2 may be the explanation of the order and direction of the $\Delta_{11}$ values. 
In summary, this study has shown that NMR can be used to evaluate association constant for $\pi$-molecular complexes. In this respect, it can serve as a valuable supplement to the Benesi-Hildebrand method $[69,70]$. The shifts of acceptor protons in a pure complex, which are also obtained in these experiments, can be rationalized in terms of the effect of ring currents of the donor on the acceptor molecule and a new contribution to the paramagnetic part of the chemical shift. From this study, it is found that $\mathbf{M X}$ can act as a CT acceptor and form CT complexes with CT donors. This study also, confirms the importance of the charge transfer forces in the interaction of $\mathbf{M X}$ with biological molecules. 


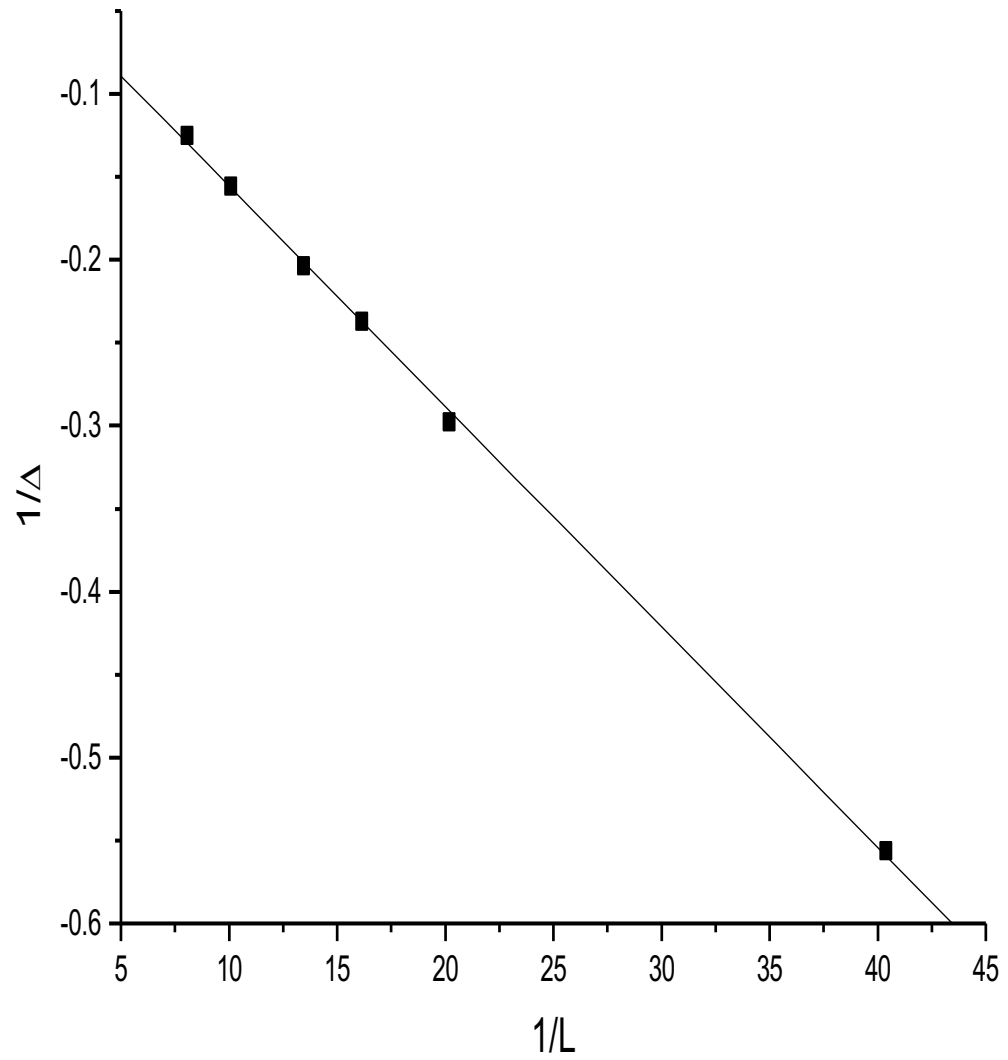

Plot of $1 / \Delta$ vs $1 / \mathrm{L}$ for $\mathrm{H}(2)$ chemical shifts in $\mathrm{HMB} / \mathrm{MX}$ charge transfer complex

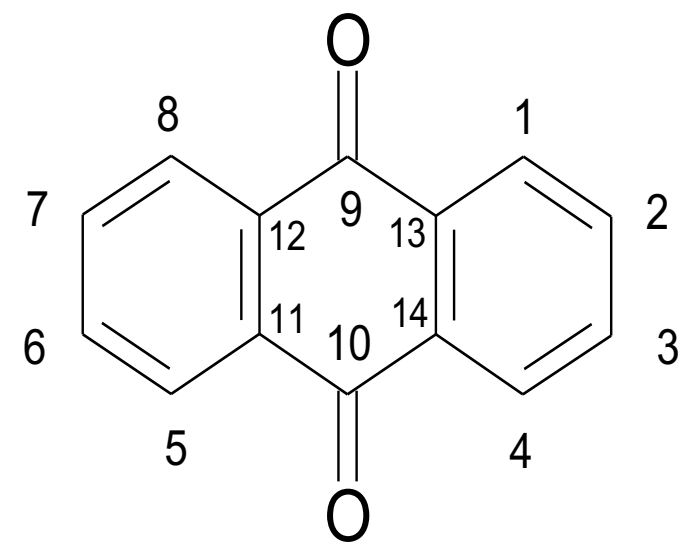

Numeration used to define tri-cyclic anthraquinone ring positions in MX.

Fig. 8. NMR spectral data and atomic numeration of the ring in MX. 


\section{CONCLUSIONS}

In this work, we investigated, computationally, the structures and energies of different intra molecular hydrogen bonding conformers of the anthraquinone anticancer drug mitoxantrone using DFT method. Five conformers within the energy range 0.000-48.495 $\mathrm{kcal} / \mathrm{mol}$ were investigated. From the calculation of the molecular reactivity descriptors and frontier molecular orbitals, HOMO and LUMO, we found that $\mathbf{M X}$ is more likely to act as an electophile than being as a nucleophile. This finding is also, confirmed by the NMR study of charge transfer complexes interaction that shows $\mathbf{M X}$ acts as an electron acceptor with known charge transfer donors. Docking results confirms the higher potency of MX compared with other anthraquinone anticancer drugs. Experimental NMR studies of the charge transfer molecular complexes of $\mathbf{M X}$ with $\mathrm{CT}$ donors prove the importance of the CT binding forces in the interaction of $\mathbf{M X}$ with biological molecules. Also, NMR studies of the charge transfer molecular complexes of MX with CT donors confirms the role of $\mathbf{M X}$ as an electron acceptor species.

\section{ACKNOWLEDGEMENT}

We are thankful for the support from Future Science-4 Program of Deanship of Scientific Research, Jazan University; Project Number: FS4-013. 


\section{REFERENCES}

1. P. Awasthi, S. Dogra, R. Barthwal, 'Multispectroscopic methods reveal different modes of interaction of anticancer drug mitoxantrone with Poly(dG-dC). Poly(dG-dC) and Poly(dA-dT).Poly(dA-dT)' Journal of Photochemistry \& Photobiology, B: Biology, Volume 127 (2013) 78-87.

2. P. Andrzej, A. S. Mariusz, A. Klimaszewska-Wisniewska, L. Gackowska, A. Zuryn, A. Grzanka, 'Cytoskeletal reorganization and cell death in mitoxantrone-treated lung cancer cells’' Acta Histochemica, 118 (2016) 784-796.

3. Z. Hajihassan, A.R. Chadegani, Interaction of mitoxantrone as an anticancer drug with chromatin proteins, core histones and H1 in solution, Int. J. Biol. Macromol. 48 (2011) 87-92.

4. Z. Hajihassan, A.R. Chadegani, Studies on the binding affinity of anticancer drug mitoxantrone to chromatin, DNA and histone proteins, J. Biom. Sci. 16 (2009) 31-38. 5. B.S. Parker, T. Buley, B.J. Evison, S.M. Cutts, G.M. Neumann, M.N. Iskander, D.R. Phillips, A molecular understanding of mitoxantrone-DNA adduct formationeffect of cytosine methylation and flanking sequences, J. Biol. Chem. 279 (2004) $18814-18823$.

6. C. Panousis, D.R. Phillips, DNA sequence specificity of mitoxantrone, Nucl. Acids Res. 22 (1994) 1342-1345.

7. B.S. Parker, S.M. Cuts, C. Cullinane, D.R. Phillips, Formaldehyde activation of mitoxantrone yields CpG and CpA specific DNA adducts, Nucl. Acid Res. 28 (2000) 982-990.

8. A. Skladanowski, J. Konopa, Mitoxantrone and ametantrone induce interstrand 
cross-links in DNA of tumor cells, Brit. J. Cancer 82 (2000) 1300-1304.

9. J. E. Benny, E. S. Brad, G. W. Keith, R. P. Don, and M. C. Suzanne, Mitoxantrone, More than Just Another Topoisomerase II Poison, Medicinal Research Reviews, 36 (2016) 248299.

10. M. Pendleton, R. Lindsey, Jr. Hunter C. A. Felix, D. Grimwade, N. Osheroff, Topoisomerase II and Leukemia, Annals of the New York Academy of Sciences, 1310 (2014) 98-110.

11. H. K. Roy, 'Compositions of muscle stimulated myokines and methods of use thereof', PCT Int. Appl. WO 196989 A (2017) 1116.

12. E. Jang, W. R. Choi, S. Y. Kim, S. S. Hong, I. Rhee, S. J. Lee, S. W. Choi, H. G. Choi, S. J. Lim, '2-Hydroxyoleic acid-inserted liposomes as a multifunctional carrier of anticancer drugs' Drug Delivery 24 (2017) 1587-1597.

13. G. Ling, T. Zhang, P. Zhang, J. Sun, Z. He, 'Synergistic and complete reversal of the multidrug resistance of mitoxantrone hydrochloride by three-in-one multifunctional lipidsodium glycocholate nanocarriers based on simultaneous BCRP and Bcl-2 inhibition' International Journal of Nanomedicine 11 (2016) 4077-4091.

14. A. Torkzadeh-Mahani, A. Mohammadi, M. Torkzadeh-Mahani, M. Mohamadi, 'A label-free electrochemical DNA biosensor for the determination of low concentrations of mitoxantrone in serum samples' International Journal of Electrochemical Science 12 (2017) 6031-6044. 
15. A. Adhikari, K. S. Mahar, 'DNA targeted anthraquinone derivatives: an important anticancer agents' International Journal of Pharmacy and Pharmaceutical Sciences 8 (2016) 17-25.

16. J. Fang, A. Wang, W. Xing, 'Application of ERIC-PCR in research of intestinal mucosal barrier change after chemotherapy in patients with acute leukemia' Xiandai Zhenduan Yu Zhiliao 25 (2014) 4577-4579.

17. Md. Abu Saleh, Md. Solayman, M. M. Hoque, M. A. K. Khan, M. G. Sarwar, M. A. Halim, 'Inhibition of DNA topoisomerase type II $\alpha$ (TOP2A) by mitoxantrone and its halogenated derivatives: a combined density functional and molecular docking study', BioMed Research International 6817502 (2016) 1-12.

18. V. V. Kostjukov, N. M. Khomytova, A. A. Hernandez Santiago, R. Licona Ibarra, D. B. Davies, M. P. Evstigneev, 'Calculation of the electrostatic charges and energies for intercalation of aromatic drug molecules with DNA' International Journal of Quantum Chemistry 111(2011) 711-721.

19. W. N. Setzer, 'DFT Computational Analysis of Caffeine $\eta$ Complexes with DNA Topoisomerase Inhibitors' Abstracts, 61st Southeast Regional Meeting of the American Chemical Society, San Juan, Puerto Rico, October SRM-628 (2009) 21-24.

20. S. Riahi, M. R. Ganjali, R. Dinarvand, S. Karamdoust, K. Bagherzadeh, P. Norouzi, 'A theoretical study on interactions between mitoxantrone as an anticancer drug and DNA: application in drug design’ Chemical Biology \& Drug Design 71 (2008) 474-482. 
21. H. Saito, H. Hirano, H. Nakagawa, K. Hoshijima, T. Ishikawa, 'Transport mechanismbased drug molecular design: a new strategy of high-speed screening and quantitative SAR analysis of $\mathrm{ABC}$ transport $\mathrm{ABCG} 2$ to design novel anticancer drugs' Progress in Cancer Drug Resistance Research (2007) 43-71.

22. G. Zagotto, S. Moro, E. Uriarte, E. Ferrazzi, G. Palu, M. Palumbo, 'Amido analogs of mitoxantrone: physico-chemical properties, molecular modeling, cellular effects and antineoplastic potential', Anti-Cancer Drug Design 12 (1997) 99-112.

23. K. X. Chen, N. Gresh, B. Pullman, 'A theoretical investigation on the sequence selective binding of mitoxantrone to double-stranded tetranucleotides', Nucleic Acids Research 14 (1986) 3799-812.

24. M. J. Frisch, G. W. Trucks, H. B. Schlegel, G. E. Scuseria, M. A. Robb, J. R. Cheeseman, G. Scalmani, V. Barone, G. A. Petersson, H. Nakatsuji, X. Li, M. Caricato, A. V. Marenich, J. Bloino, B. G. Janesko, R. Gomperts, B. Mennucci, H. P. Hratchian, J. V. Ortiz, A. F. Izmaylov, J. L. Sonnenberg, D. Williams-Young, F. Ding, F. Lipparini, F. Egidi, J. Goings, B. Peng, A. Petrone,T. Henderson, D. Ranasinghe, V. G. Zakrzewski, J. Gao, N. Rega, G. Zheng, W. Liang, M. Hada, M. Ehara, K. Toyota, R. Fukuda, J. Hasegawa, M. Ishida, T. Nakajima, Y. Honda, O. Kitao, H. Nakai, T. Vreven, K. Throssell, J. A. Montgomery, Jr., J. E. Peralta, F. Ogliaro, M. J. Bearpark, J. J. Heyd, E. N. Brothers, K. N. Kudin, V. N. Staroverov, T. A. Keith, R. Kobayashi, J. Normand, K. Raghavachari, A. P. Rendell, J. C. Burant, S. S. Iyengar, J. Tomasi, M. Cossi, J. M. Millam, M. Klene, C. Adamo, R. Cammi, J. W. Ochterski, R. L. Martin, K. Morokuma, O. Farkas, J. B. Foresman, and D. J. Fox, Gaussian, Inc., Wallingford CT, (2016). 
25. B. Delley, J. Chem. Phys. 92 (1990) 508.

26. B. Delley, J. Chem. Phys. 113 (2000) 7756.

27. Accelrys Software Inc., Material Studio Modeling Environment, Release v7.0, San Diego: Accelrys Software Inc., (2013).

28. T. M. EL-Gogary, Spectral and Computational behavior of some Anthraquinones DNA-Affinic Agents, Canadian Journal of Analytical Science and Spectroscopy, 48 (2003) 314-319.

29. T. M. EL-Gogary, Molecular Complexes of some Anthraquinone anti-cancer Drugs: Experimental and Computational Study, Spectrochimica Acta part A, 59 (2003) 1009-1015.

30. K. Fukui, A Molecular Orbital Theory of Reactivity in Aromatic Hydrocarbons, J. Chem. Phys. 20 (1952) 722; Molecular Orbital Theory of Orientation in Aromatic, Heteroaromatic, and Other Conjugated Molecules 22 (1954) 1433.

31. R. G. Parr, W. Yang, Density functional approach to the frontier-electron theory of chemical reactivity J. Am. Chem. Soc. 106 (1984) 4049.

32. W. Yang, R. G. Parr, Hardness, softness, and the Fukui function in the electronic theory of metals and catalysis, Proc. Natl. Acad. Sci. U.S.A. 82 (1985) 6723-6726.

33. M. F. Brana, M. Cacho, A. Gradillas, B. De Pascual-Teresa, and A. Ramos, "Intercalators as anticancer drugs," Current Pharma-ceutical Design, vol. 7, no. 17, pp. 1745-1780, 2001.

34. C. P. Burns, B. N. Haugstad, and J. A. North, "Membrane transport of mitoxantrone by L1210 leukemia cells," Biochemical Pharmacology, vol. 36, no. 6, pp. 857-860, 1987. 
35. S. Christmann-Franck, H.-O. Bertrand, A. Goupil-Lamy et al., "Structure-based virtual screening: an application to human topoisomerase II $\alpha$," Journal of Medicinal Chemistry, vol. 47 , no. 27 , pp. $6840-6853,2004$.

36. Md. Abu Saleh, Md. Solayman, Mohammad Mazharol Hoque, Mohammad A. K. Khan, Mohammed G. Sarwar, and Mohammad A. Halim, Inhibition of DNA Topoisomerase Type II $\alpha$ (TOP2A) by Mitoxantrone and Its Halogenated Derivatives: A Combined Density Functional and Molecular Docking Study, Hindawi Publishing Corporation BioMed Research International Volume 2016, Article ID 6817502, 12 pages http://dx.doi.org/10.1155/2016/6817502

37. A. Wehenkel, P. Fernandez, M. Bellinzoni, V. Catherinot, N. Barilone, G. Labesse, M. Jackson, P. M. Alzari, The structure of PknB in complex with Mitoxantrone, an ATP-competitive inhibitor, suggests a mode of protein kinase regulation in mycobacteria Febs Lett. 580 (2006) 3018-3022.

38. L. Malinina, M. Soler-Lopez, J. Aymami, J. A. Subirana, Intercalation of an Acridine-Peptide Drug in an AA/TT Base Step in the Crystal Structure of [d(CGCGAATTCGCG)]2 with Six Duplexes and Seven Mg2+ Ions in the Asymmetric Unit, Biochemistry 41 (2002) 9341-9348.

39. Discovery Studio 2.0. Accelrys, Inc., San Diego, CA, (2003).

40. J. S. Al-Otaibi, P. T. Spittle and T. M. EL Gogary, "Interaction of anthraquinone anti-cancer drugs with DNA; Experimental and computational quantum chemical study", Journal of Molecular Structure 1127 (2017) 751-760. 
41. Pritish Varadwaj, Krishna Misra, Anju Sharma, Rajnish Kumar, Mitoxantrone: an agent with promises for anticancer therapies, Electronic Journal of Biology, 6 (2010) 3642.

42. M. Sirajuddin, S. Ali, A. Badshah, Drug-DNA interactions and their study by UVVisible, fluorescence spectroscopies and cyclic voltametry, Journal of Photochemistry and Photobiology B: Biology 124 (2013) 1-19.

43. A. A. H. Saeed, B. H. B. Kunda and K. A. A. Alrazaq, Sepct. Lett., 26 (1993) 403.

44. L. R. Melby, R. J. Harder, W. R. Hertler, W. Mahler, R. E. Benson and W. E. Mochel, Substituted Quinodimethans II Anion-radical Derivatives and Complexes of 7,7,8,8-Tetracyanoquinodimethan, J. Am. Chem. Soc., 84 (1962) 3374-3387.

45. H. Boch, K. Ziemer, C. Nather, H. Schodel, M. Kleine, M. Sievert, Zeitschrift Fur Naturforschung section B-A J. Chem. Sci., 51 (1996) 1538.

46. H. Boch, M. Sievert, H. Schodel, M. Kleine, ibid., 51 (1996) 1521.

47. M. M. Ayad, Zeitschrift Fur Physikalische Chemie-Inter. J. in Phys. Chem. and Chem. Pysics, 187 (1994) 123.

48. M. M. Ayad and S. A. Eldaly, ibid., 190 (1995) 211.

49. C. Kabuto, Y. Fukazawa, T. Suzuki, Y. Yamashita, T. Miyashi, and T. Mukai, Crystal structures of molecular complexes of 2-chloro-11,11,12,12tetracyanoanthraquinodimethane with benzene (1:1) and pyrene (2:1): A novel type of charge transfer complexes, Tetrahedron lett., 27 (1986) 925-928.

50. R. E. Merrifield and W. D. Phillips, J. Am. Chem. Soc., 80 (1958) 22778.

51. R. Foster and I. B. C. Matheson, An optical determination of the stability of the fluoranil-hexamethylbenzene complex in solution, J. Chem. Soc. (B), (1970) 1713-1714. 
52. K. Kulinowski, I. R. Gould, N. S. Ferris, and A. B. Myers, Spectroscopic, Kinetic, and Thermodynamic Deuterium Isotope in the Hexamethylbenzene/Tetracyanoethylene Charge-Transfer Complex, J. Phys. Chem., 99 (1995) 17715-1723.

53. J. Ramstein, M. Dourlent, M. Lang, Interaction between proflavine and deoxyribonucleic acid influence of DNA base composition, Biochem. Biophys. Res. Commun., 47 (1972) 874-82.

54. F. Takahashi and N. C. Li, J. Phys. Chem., 69 (1965) 1922.

55. F. Takahashi and N. C. Li, J. Am. Chem., Soc., 88 (1966) 1117.

56. P. J. Trotter and M.W. Hanna, Molecular Complex Equilibria. Solution Ideality, Solvent Interactions, and Concentration-Scale Dependence, J. Am. Chem. Soc., 88 (1966) 3724-3729.

57. T. C. Nehman and A. I. Popov, Charge-Transfer Complexes of Mono- and Disubstituted Tetrazoles with $\pi$-Electron Acceptors, J. Phys. Chem., 70 (1966) 3688-3693.

58. S. Kyushin, Y. BabaF, Y. Nakadaira and M. Ohashi, Main Group Metal Chemistry, 18 (1995) 299.

59. L. Seung-Hwan, I. Koichiro, 0. Joe, A. Koji and S. Manabu, Characterisation of 'sandwich' charge-transfer complexes composed of bis-anthracene donors and aromatic acceptors, J. Chem. Soc. Perkin Trans. 2 (1996) 847-852.

60. M. W. Hanna and A. L. Ashbaugh, Nuclear Magnetic Resonance Study of Molecular Complexes of 7,7,8,8-Tetracyanoquinodimethane and Aromatic Donors, J. Phys. Chem., 68 (1964) 811-816. 
61. R. Foster and C. A. Fyfe, Interaction of electron acceptors with bases. Part 15. Determination of association constants of organic charge-transfer complexes by n.m.r. spectroscopy, Trans. Faraday Soc., 61 (1965) 1626.

62. R. Foster and C. A. Fyfe, Fluorine Nuclear Magnetic Resonance Determination of the Association Constant of an Organic Electron-donor-Acceptor Complex, Chem. Comm., (1965) 642-642.

63. R. Foster and C. A. Fyfe, Electron-donor-acceptor complex formation by compounds of biological interest II. The association constants of various 1,4-dinitrobenzenephenothiazine drug complexes, Biochem. Et Biophys. Acta, 112 (1966) 490-495.

64. R. Foster and C. A. Fyfe, Interaction of electron acceptors with bases. Part 20. Application of an n.m.r. method to determination of stability of some organic chargetransfer complexes in solution Trans Faraday Soc., 62 (1966) 1400-1405.

65. R. Foster and C. A. Fyfe, Simultaneous Determination of Several Charge-transfer Complex Association Constants using Nuclear Magnetic Resonance, Nature, 213 (1967) $591-591$.

66. R. Foster and C. A. Fyfe, Electron-donor-acceptor complex formation by compounds of biological interest. Part III. Indole complexes, J. Chem. Soc., (B), 926 (1966). 
67. G. Fraenkel, R. F. Carter, A. McLachlan, and J. H. Richards, Chemical Shifts in C5H5, C6H6 and C7H7+; Chemical Shifts and $\pi$-Electron Densities, J. Am. Chem. Soc., 82 (1960) 5846.

68. W. G. Schneider, DIRECTED SOLUTE-SOLVENT INTERACTIONS IN BENZENE SOLUTIONS, J. Phys. Chem, 66 (1962) 2653-2657.

69. H. Benesi and Hildebrand, Solubility of Iodine in 1,2- and 1,1-Dichloroethanes, cisand trans-Dichloroethylenes and Perfluoro-n-heptane, J. Am. Chem. Soc., 70 (1948) 39783981.

70. H. Benesi and Hildebrand, A Spectrophotometric Investigation of the Interaction of Iodine with Aromatic Hydrocarbons, J Am. Chem. Soc., 71 (1949) 2703-2707. 


\section{Figure captions:}

Fig. 1. Optimized Structure of $\mathbf{M X}$ conformers showing atomic numeration, H-bonding and relative energy.

Fig. 2. Calculated natural atomic charges of $\mathbf{M X}$.

Fig. 3. Important molecular orbitals surface with their energies and molecular electrostatic potential of MX.

Fig. 4. 3D nonbonding interactions of $\mathbf{M X}$ with ATP active site of CDK2 and DNA. a) showing the $\mathbf{M X}$ in the active site sphere of $\mathrm{CDK} 2, \mathrm{~b}$ ) hydrogen bonding interaction between MX and CDK2 active site, c) showing a focused view of hydrogen bonding interaction between MX and CDK2 active site, d) showing MX/DNA intercalation complex, d) and f) showing the hydrogen bonding interaction between MX and DNA bases.

Fig. 5. ${ }^{1} \mathrm{H}$ NMR spectrum of $\mathrm{H}(2)$ of $\mathbf{M X}$ in its mixtures with PY; concentration of $\mathbf{M X}$ is $6.031 \times 10^{-3} \mathrm{M}$ and concentrations of $\mathrm{PY}$ from bottom to top are: $0.0,0.0250,0.0512,0.0637$, 0.0761 , and $0.1016 \mathrm{M}$.

Fig. 6. ${ }^{1} \mathrm{H}$ NMR spectrum of $\mathrm{H}(6)$ of $\mathbf{M X}$ in its mixtures with PY; concentration of $\mathbf{M X}$ is $6.031 \times 10^{-3} \mathrm{M}$ and concentrations of PY from bottom to top are: $0.0,0.0250,0.0512,0.0637$, 0.0761 , and $0.1016 \mathrm{M}$.

Fig. 7. ${ }^{1} \mathrm{H}$ NMR spectrum of $\mathrm{H}(5)$ of $\mathbf{M X}$ in its mixtures with $\mathrm{PY}$; concentration of $\mathbf{M X}$ is $6.031 \times 10^{-3} \mathrm{M}$ and concentrations of PY from bottom to top are: $0.0,0.0250,0.0512,0.0637$, 0.0761 , and $0.1016 \mathrm{M}$.

Fig. 8. NMR spectral data and atomic numeration of the ring in MX. 